\title{
A COMPARATIVE EARTHWORK AND COST ANALYSIS OF IMPROVING AN EXISTING RAILLWAY LİNE AND CONSTRUCTING A NEW HIGH-SPEED LINE IN TURKEY
}

\author{
K. A. Gumus ${ }^{\mathrm{a}}$, V. E. Gulal ${ }^{\mathrm{b}}$ \\ a Turkish State Railways, Department of Survey, Project and Investment, 06330 Altındag, Ankara, Turkey - \\ kerimaykutgms@gmail.com \\ b Yildiz Technical University, Department of Geomatics Engineering, 34220 Davutpasa, Istanbul, Turkey - egulal@yildiz.edu.tr
}

KEY WORDS: High-Speed Railways, High-Speed Track, Track Geometry, Track Design, Cost Analysis

\begin{abstract}
:
In the past few decades, high-speed railways have become an important transportation system due to their high operational speed, and globally, the networks of these railways have been extended. In addition, there is ongoing work on the construction of new high-speed railways as well as improving existing lines to achieve the same operational speed. To contribute to high-speed railway works in Turkey, this study compared two high-speed railway lines; an existing conventional line, the design of which was improved, and a new high-speed line. The design of an existing conventional railway line was improved according to optimal geometric characteristics of high-speed railways and an alternative line was simulated. These two lines were evaluated on three different types of land in terms of the required volume of earthworks, engineering structures and total cost. The results show that the length of the conventional line was reduced after the improvement process; however, new engineering structures are needed. Furthermore, compared to the alternative line, the track length and total length of engineering structures required for the improvement of the existing line was shorter and the volume of required earthworks was less resulting in lower costs.
\end{abstract}

\section{INTRODUCTION}

As with other transportation systems, railways consist of multiple elements including the route network, vehicle fleet and the operation system (Yalçın, 2007). There are two types of railways; high-speed and conventional. According to the directive 94/48/EC of the Council of the European Union, the term 'highspeed' covers all railway express services operating at speeds within the 200 to $300 \mathrm{~km} / \mathrm{h}$ range (Mundrey, 2010) and railways operating at a speed below this range are considered conventional. Due to their different requirements in terms of speed, the geometric specifications, infrastructure and superstructure of high-speed and conventional railways differ (Ekim, 2010). After the work on high-speed railways began in Japan in 1964, there has been a rapid expansion of high-speed railway networks, particularly in Europe and Asia (Esveld, 2010).

In Turkey, the construction and development of high-speed railways gained more importance and speed after 2000. This study aimed to contribute to high-speed railway works in Turkey by comparing two high-speed railway lines; an existing conventional line, the design of which was improved, and an alternative line.

In the literature, there are several studies on the geometric characteristics and design of railway lines. In this study, the design parameters for the improvement of the existing line and simulation of the alternative were based on previous work by two researchers. The first is Lindahl (2001), who compared the geometric characteristics of high-speed railways used in the world and a simulated line. Based on the results, the author suggested new limits regarding the geometric characteristics of high-speed railways. The second is Hodas (2014), who created three designs for high-speed railway lines using 3D modeling software in accordance with the standards provided by the European Committee for Standardization (CEN), the newly prepared and current geometric standards for the Slovak
Railways, and compared the designs with each other. The author concluded that the design work entails complicated procedures with the design of both slow- and high-speed railway lines being equally difficult. However, Hodas added that these two types of lines have different design parameters and the security of railway line should be maintained as the project speed increases. In addition, using 3D modeling software has certain advantages for designing railways.

In this study, first, the geometric characteristics used in the design of high-speed railways were identified. Then, the geometry of an existing conventional line in Turkey was improved and an alternative line was simulated. The relevant engineering structures were determined and the volume of earthworks required for both lines was calculated. Finally, the approximate total costs of constructing these lines regarding earthworks and engineering structures were separately calculated and compared to each other.

\section{METHOD}

\subsection{Geometric characteristics of high-speed railways}

With the increase in train speeds, analyzing track geometry has become more important in the design of new high-speed lines since safety should be guaranteed and a high level comfort is desired (Vermeij, 2000). In this section, the limit values for the geometric characteristics of high-speed railways are examined to determine the parameters to be used in the design process.

\subsubsection{Horizontal geometry}

Table 1 presents the boundary limits of passenger-dedicated high-speed railway lines at a speed of $300 \mathrm{~km} / \mathrm{h}$. 


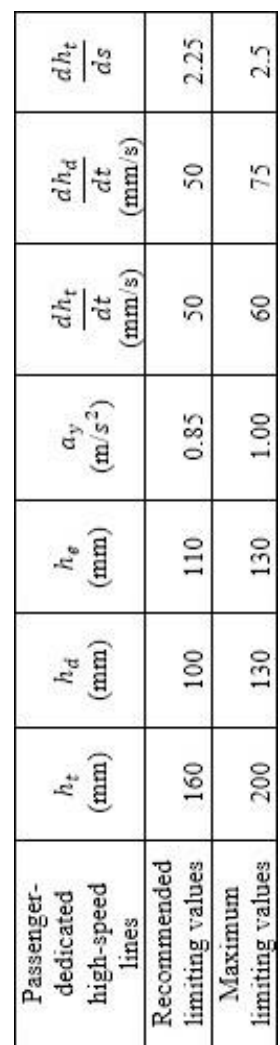

Table 1. Normal and exceptional limit values recommended by TSI and CEN standards (Lindahl, 2001).

TSI: Technical Specification for Interoperability, CEN: European Committee for Standardization.

The explanation of the symbols used in the table is given below: $h_{t}=$ applied cant,

$h_{d}=$ cant deficiency,

$h_{e}=$ cant excess,

$a_{y}=$ lateral acceleration,

$\frac{d h_{t}}{d t}=$ rate of applied cant as a function of time,

$\frac{d h_{d}}{d t}=$ rate of cant deficiency as a function of time,

$\frac{d h_{t}}{d s}=$ rate of applied cant as a function of length.

The cant deficiency $(130,100 \mathrm{~mm})$ and applied cant $(200,160$ $\mathrm{mm}$ ) values recommended for passenger-dedicated high-speed railway lines at $300 \mathrm{~km} / \mathrm{h}$ speed were obtained by calculating the minimum horizontal curve radii with the following equation (CEN, 2010) and ( TSI, 2000). In the design process, the cant and cant deficiency values were assumed to be $160 \mathrm{~mm}$ and $100 \mathrm{~mm}$, respectively.

$R_{\min }=11.8 \cdot \frac{V_{\max }^{2}}{h_{t}+h_{d}}$

Where $V_{\text {max }}=$ maximum design speed

$R_{\min }=$ minimum horizontal curve radius

Table 2 presents the curve radii obtained from Equation (1)

\begin{tabular}{|c|c|c|c|}
\hline$V_{\text {maks }}(\mathrm{km} / \mathrm{h})$ & $h_{t}(\mathrm{~mm})$ & $h_{d}(\mathrm{~mm})$ & $R_{\min }(\mathrm{m})$ \\
\hline 300 & 160 & 100 & 4,084 \\
\hline 300 & 160 & 130 & 3,662 \\
\hline 300 & 200 & 100 & 3,540 \\
\hline 300 & 200 & 130 & 3,218 \\
\hline
\end{tabular}

Table 2. Calculated curve radii
To facilitate the application of the resulting values in the field and avoid adverse safety consequences due to mistakes during implementation, the values were rounded up to the nearest multiple of 50, and the minimum horizontal curve radii were assumed to be $3,250 \mathrm{~m}, 3,550 \mathrm{~m}, 3,700 \mathrm{~m}$, and 4,100 $\mathrm{m}$. The minimum curve radius was taken as $5,000 \mathrm{~m}$ in the design process.

The length of the transition curves was determined by the limiting values of the rate of cant deficiency as a function of time $\left(\frac{d h_{t}}{d t}\right)$ and the rate of cant as a function of length $\left(\frac{d h_{t}}{d s}\right)$. According to the standards provided by the European Committee for Standardization (CEN), the length of the transition curve should be the longest value derived from the following formulas (CEN, 2010):

$$
\begin{aligned}
& L_{t} \geq \frac{V_{\text {maks }}}{3.6} \cdot \Delta h_{d}\left(\frac{d h_{d}}{d_{t}}\right)_{\text {lim }}^{-1} \\
& L_{t} \geq \Delta h_{t}\left(\frac{d h_{t}}{d s}\right)_{\text {lim }}^{-1}
\end{aligned}
$$

Where $L_{t}=$ length of transition curve

$\Delta h_{d}=$ variation of cant deficiency

$\Delta h_{t}=$ variation of application cant

$\frac{d h_{d}}{d t}=$ rate of cant deficiency as a function of time

$\frac{d h_{t}}{d s}=$ rate of application cant as a function of length

From Equations 2 and 3, the lengths of the transition curves were obtained as $167 \mathrm{~m}$ and $71 \mathrm{~m}$, respectively. However, the minimum length of the transition curves was taken as $400 \mathrm{~m}$ in the analysis process (Table 3 ) and $500 \mathrm{~m}$ in the design process.

Rail transport moving with a constant speed through a curve is subjected to various forces, which affect the safety of the vehicle and the comfort of the traveler. The magnitudes of the forces are the lateral acceleration, rate of lateral acceleration as a function of time, rate of applied cant as a function of time, rate of applied cant as a function of length and rate of cant deficiency as a function of time. Equations 4 to 7 taken from CEN (2010) calculate the forces that arise in horizontal curves for $300 \mathrm{~km} / \mathrm{h}$ maximum and $200 \mathrm{~km} / \mathrm{h}$ minimum design speed, constant cant and cant deficiency values and transition curves with $400 \mathrm{~m}, 450$ $\mathrm{m}$ and $500 \mathrm{~m}$ lengths and horizontal curve radii with of $3,250 \mathrm{~m}$, $3,550 \mathrm{~m}, 3,700 \mathrm{~m}, 4,100 \mathrm{~m}, 5,000 \mathrm{~m}$.

$$
\begin{aligned}
& a_{y}=\frac{V_{\max }^{2}}{R}-g \cdot \frac{h_{t}}{2 b_{0}} \\
& \frac{d h_{t}}{d t}=\frac{\Delta h_{t \cdot V_{\text {max }}}}{L_{t}} \\
& \frac{d h_{d}}{d t}=\frac{\Delta h_{d \cdot V_{\max }}}{L_{t}} \\
& \frac{d h_{t}}{d s}=\frac{h_{t}}{L_{\mathrm{t}}}
\end{aligned}
$$

Where $a_{y}=$ lateral acceleration

$$
\begin{aligned}
& \frac{d h_{t}}{d t}=\text { rate of application cant as a function of time } \\
& g=\text { gravitational acceleration } \\
& 2 b_{0}=\text { track gauge }
\end{aligned}
$$

In the design process, lateral acceleration, the rates of applied cant as a function of time, cant deficiency as a function of time and applied cant as a function of length were taken as $0.85 \mathrm{~m} / \mathrm{s}^{2}$, $50 \mathrm{~mm} / \mathrm{s}, 50 \mathrm{~mm} / \mathrm{s}$ and 2.25 , respectively. Table 3 presents the 
magnitudes of the forces that arise in curves with $3,250 \mathrm{~m}, 3,550$ $\mathrm{m}, 3,700 \mathrm{~m}, 4,100$ and $5,000 \mathrm{~m}$ radii at $300 \mathrm{~km} / \mathrm{h}$ maximum and $200 \mathrm{~km} / \mathrm{h}$ minimum design speed, $160 \mathrm{~mm}$ maximum applied cant and $100 \mathrm{~mm}$ maximum cant deficiency, respectively.

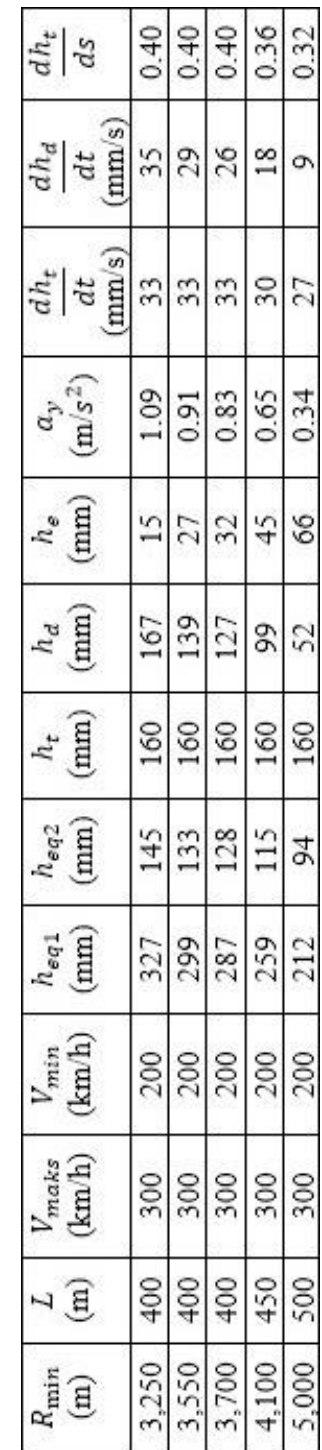

Table 3. Magnitudes of forces affecting the vehicle in the curves

In Table $3, L$ refers to the transition curve, $V_{\min }$ is the minimum design speed, $h_{e q 1}$ represents the equilibrium cant for the maximum design speed, and $h_{e q 2}$ refers to the equilibrium cant for the minimum design speed. The minimum horizontal curve radius was calculated as $4,100 \mathrm{~m}$ but it was taken as $5,000 \mathrm{~m}$ to provide a comfortable ride and increase the operation speed in future. The parameters assessed for $5,000 \mathrm{~m}$ horizontal curve radius and $500 \mathrm{~m}$ transition curve do not exceed the limit values given in Table 3. Through these analyses, optimal horizontal geometric parameters were identified to be used in the design process.

\subsubsection{Vertical Geometry}

Table 4 presents the limit values of vertical curve radius according to the CEN standards.

\begin{tabular}{|c|c|}
\hline & $\begin{array}{c}\text { Passenger-dedicated high- } \\
\text { speed lines } \\
250<\mathrm{V} \leq 300\end{array}$ \\
\hline $\begin{array}{c}\text { Recommended limiting } \\
\text { values }(\mathrm{m})\end{array}$ & $0.35 . V_{\text {maks }}^{2}$ \\
\hline $\begin{array}{c}\text { Minimum limiting values } \\
(\mathrm{m})\end{array}$ & $0.175 . V_{\text {maks }}^{2}$ \\
\hline
\end{tabular}

Table 4 Limit values of vertical curve radius (CEN, 2010)

The recommended limit values of the vertical curve radius were obtained as $31,500 \mathrm{~m}$ for the maximum design speed $(300 \mathrm{~km} / \mathrm{h})$ but for the implementation, the minimum vertical curve radius value was taken as $30,000 \mathrm{~m}$. During the design process, $0.35 \%$ gradient should be allowed for main tracks. However, the slope of the sliding average profile over $10 \mathrm{~km}$ should be less than or equal to $0.25 \%$ or the maximum length of continuous $0.35 \%$ gradient should not exceed $6 \mathrm{~km}$ (TSI, 2000). In this study, the maximum gradient was accepted as $2.20 \%$ in the design process.

\subsubsection{Selected geometric characteristics}

The following geometric parameters were selected to be used in the design of the curves for the improved and alternative passenger-dedicated railway lines:

- $300 \mathrm{~km} / \mathrm{h}$ maximum design speed,

- $200 \mathrm{~km} / \mathrm{h}$ minimum design speed,

- $160 \mathrm{~mm}$ applied cant,

- $100 \mathrm{~mm}$ cant deficiency,

- $\quad 5000 \mathrm{~m}$ minimum horizontal curve radius,

- $30000 \mathrm{~m}$ minimum vertical curve radius,

- $2.20 \%$ maximum gradient.

Table 5 presents the horizontal geometry design parameters used in the implementations.

\begin{tabular}{|c|c|c|c|c|c|}
\hline $\begin{array}{c}R_{\min } \\
(\mathrm{m})\end{array}$ & $\begin{array}{c}V_{\max } \\
(\mathrm{km} / \mathrm{h})\end{array}$ & $\begin{array}{c}V_{\min } \\
(\mathrm{km} / \mathrm{h})\end{array}$ & $\begin{array}{c}h_{t} \\
(\mathrm{~mm})\end{array}$ & $\begin{array}{c}h_{d} \\
(\mathrm{~mm})\end{array}$ & $\begin{array}{c}h_{e} \\
(\mathrm{~mm})\end{array}$ \\
\hline 5000 & 300 & 200 & 160 & 100 & 110 \\
\hline \multicolumn{5}{c}{ Table 5. Limit values for geometric parameters used } \\
in the design of the improved and alternative high- \\
speed railway lines
\end{tabular}

\subsection{Creation of the lines}

This section presents the simulation of two railway lines, a geometrically improved existing conventional line and an alternative line for three different land types in accordance with the limit values given in the previous section. After the creation process, the engineering structures and the volume of earthworks required for each line was separately calculated. The determination of these values allows a cost analysis to be performed (Szwaczkiewicz, 2014). Finally, the approximate costs of the lines were calculated and compared.

The design of construction, reconstruction or modernization of railway tracks should be performed using 3D software according to digital design documentation (Hodas, 2014). Therefore, in this study, Bentley Rail Track Software was used for track design, volume calculation and determination of required engineering structures. The unit prices of Turkish State Railways (TCDD) were used to calculate approximate costs. The volume of earthworks and total length of engineering structures required for the improved and alternative lines were multiplied by unit prices to achieve the total cost of each line. 


\subsubsection{Implementation 1}

The first implementation was carried out on flat-type land, which was not rolling and mountainous. An existing conventional line of 31,837 m length with a minimum curve radius of $850 \mathrm{~m}$, maximum curve radius of $4,000 \mathrm{~m}$, and a maximum gradient of $2.20 \%$ was geometrically improved using the design parameters identified in the previous stage.

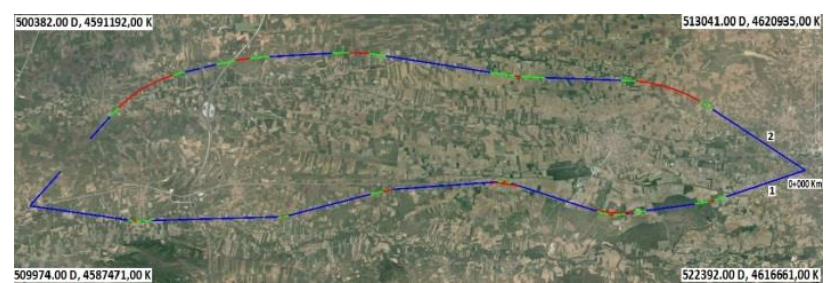

Figure 1. Routes for the existing and improved conventional lines for Implementation 1

In Figure 1, Line 1 shows the existing conventional railway and its state after improvement, and Line 2 presents an alternative track to the existing conventional line. The lines in blue indicate the straight parts of the tracks while green shows the transition curves and red presents the curves.

The geometrical parameters used for the improvement of the existing line were as follows: Minimum horizontal curve radius $5,000 \mathrm{~m}$, transition curve length $500 \mathrm{~m}$, maximum applied cant $160 \mathrm{~mm}$, minimum vertical curve radius $30,000 \mathrm{~m}$, and maximum gradient $2.20 \%$. For the straight parts of the conventional line, the horizontal curves had a transition curve length of $500 \mathrm{~m}$ and a horizontal curve radius of 5,000 $\mathrm{m}$; therefore, the improvement was performed only on the curves. The volume of earthworks and cost calculated for the improvement of $31,818 \mathrm{~m}$ long line are given in Tables 6 and 7, respectively.

\begin{tabular}{|c|c|}
\hline Cut $\left(\mathrm{m}^{3}\right)$ & Fill $\left(\mathrm{m}^{3}\right)$ \\
\hline $3,351,632.21$ & $1,053,596.25$ \\
\hline
\end{tabular}

Table 6. Volume of earthworks required for the improvement of the existing line on flat land

\begin{tabular}{|c|c|}
\hline Cut (TL) & Fill (TL) \\
\hline $26,813,057.66$ & $1,126,171.76$ \\
\hline Total (TL) & $27,939,229.42$ \\
\hline
\end{tabular}

Table 7. Approximate total cost of the improvement of the existing line on flat land

In the following stage, a $34,600 \mathrm{~m}$ alternative track with $2.20 \%$ gradient was created. For this line, the minimum and maximum horizontal curve radii were $5,000 \mathrm{~m}$ and $10,000 \mathrm{~m}$, respectively; the minimum and maximum transition curve lengths were $500 \mathrm{~m}$ and $1,000 \mathrm{~m}$ respectively; the minimum vertical curve radius was $30,000 \mathrm{~m}$; and the minimum and maximum applied cant values were $100 \mathrm{~mm}$ and $160 \mathrm{~mm}$, respectively. Tables 8,9 and 10 present the calculated volume of earthworks, total length of engineering structures and total cost for the alternative line.

\begin{tabular}{|c|c|}
\hline Cut $\left(\mathrm{m}^{3}\right)$ & Fill $\left(\mathrm{m}^{3}\right)$ \\
\hline $6,914,716.96$ & $1,365,259.30$ \\
\hline
\end{tabular}

Table 8. Volume of earthworks required for the construction of the alternative line on flat land

\begin{tabular}{|c|c|}
\hline Bridge $(\mathrm{m})$ & Tunnel $(\mathrm{m})$ \\
\hline 300 & 0 \\
\hline
\end{tabular}

Table 9. Total length of engineering structures required for the construction of an alternative line on flat land

\begin{tabular}{|c|c|c|}
\hline Cut (TL) & Fill (TL) & Bridge (TL) \\
\hline $55,317,735.70$ & $12,287,333.70$ & $4,800,000$ \\
\hline & Total (TL) & $72,405,069.38$ \\
\cline { 2 - 3 }
\end{tabular}

Table 10. Approximate total cost of constructing an alternative line on flat land

\subsubsection{Implementation 2}

The second implementation was carried out on an existing conventional line of $43,000 \mathrm{~m}$ in length on rolling-type land. This line had a minimum curve radius of $380 \mathrm{~m}$, maximum curve radius of $3,005 \mathrm{~m}$ and maximum gradient of $1.60 \%$.

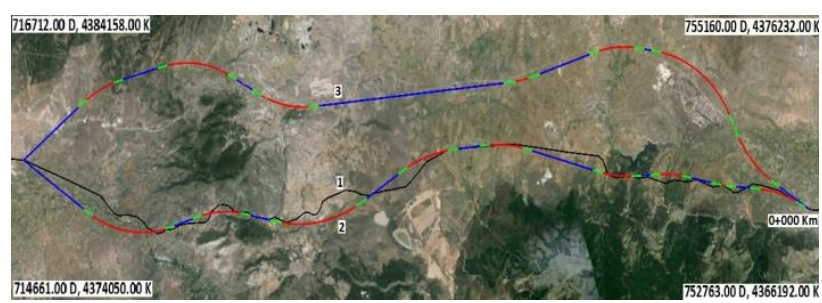

Figure 2. Routes for the existing and improved conventional line for Implementation 2

In Figure 2, Line 1 in black indicates the existing conventional railway, Line 2 represents the improved state of the conventional railway and Line 3 presents an alternative track to the conventional line. The blue lines represent the straight parts of the tracks, green represents the transition curves, and red indicates the curves.

The following geometrical parameters for the horizontal curves were used to improve the design of the existing line: $5,000 \mathrm{~m}$ minimum and 6,000 m maximum horizontal curve radius, $500 \mathrm{~m}$ minimum and $600 \mathrm{~m}$ maximum transition curve length, $160 \mathrm{~mm}$ applied cant, $30,000 \mathrm{~m}$ minimum vertical curve is and $2.20 \%$ maximum gradient. The volume of earthworks, total length of engineering structures and approximate cost calculated for the improvement of 40,759 $\mathrm{m}$ long line are presented in Tables 11,12 and 13 , respectively.

\begin{tabular}{|c|c|}
\hline Cut $\left(\mathrm{m}^{3}\right)$ & Fill $\left(\mathrm{m}^{3}\right)$ \\
\hline $4,197,751.31$ & $1,526,852.01$ \\
\hline
\end{tabular}

Table 11. Volume of earthworks required for the improvement of the conventional line on rolling land

\begin{tabular}{|c|c|}
\hline Bridge $(\mathrm{m})$ & Tunnel $(\mathrm{m})$ \\
\hline 1,870 & 990 \\
\hline
\end{tabular}

Table 12. Total length of engineering structures required for the improvement of the conventional line on rolling land

\begin{tabular}{|c|c|c|c|}
\hline Cut (TL) & Fill (TL) & $\begin{array}{c}\text { Bridge } \\
\text { (TL) }\end{array}$ & Tunnel (TL) \\
\hline $33,582,010.51$ & $13,741,668.05$ & $29,920,000$ & $39,600,000$ \\
\hline \multicolumn{2}{|r}{} & Total (TL) & $116,843,678.56$ \\
\cline { 3 - 4 }
\end{tabular}

Table 13. Approximate total cost of improving the conventional line on rolling land

In the second stage of Implementation 2, a 43,050 m alternative track with $2.20 \%$ gradient was created. For this line, the minimum and maximum horizontal curve radii were $5,000 \mathrm{~m}$ $6,000 \mathrm{~m}$, respectively; the minimum and maximum transition curve lengths were $500 \mathrm{~m} 600 \mathrm{~m}$, respectively, the minimum vertical curve radius was $30,000 \mathrm{~m}$, and the maximum applied cant was $160 \mathrm{~mm}$. Tables 14, 15 and 16 present the volume of 
earthworks, total length of engineering structures, and approximate cost calculated for the alternative line.

\begin{tabular}{|c|c|}
\hline Cut $\left(\mathrm{m}^{3}\right)$ & Fill $\left(\mathrm{m}^{3}\right)$ \\
\hline $927,211.80$ & $1,263,432.20$ \\
\hline
\end{tabular}

Table 14. Volume of earthworks required for the construction of an alternative line on rolling land

\begin{tabular}{|c|c|}
\hline Bridge $(\mathrm{m})$ & Tunnel $(\mathrm{m})$ \\
\hline 6,540 & 1,920 \\
\hline
\end{tabular}

Table 15. Total length of engineering structures required for the construction of an alternative line on rolling land

\begin{tabular}{|c|c|c|c|}
\hline Cut (TL) & Fill (TL) & Bridge (TL) & Tunnel (TL) \\
\hline $7,417,694.40$ & $11,370,889.79$ & $104,640,000$ & 0,000 \\
\hline & & Total (TL) & $200,228,584.20$ \\
\hline
\end{tabular}

Table 16. Approximate total cost of constructing an alternative line on rolling land

\subsubsection{Implementation 3}

For the third implementation, a mountainous type of land was chosen. The conventional line to be improved was $78,800 \mathrm{~m}$ in length with a minimum curve radius of $294 \mathrm{~m}$, maximum curve radius of 3,000 $\mathrm{m}$ and a maximum gradient of $2.90 \%$.

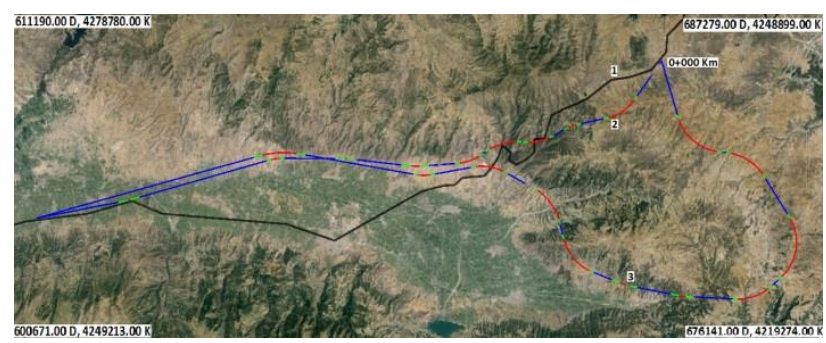

Figure 3. Routes for the existing and improved lines for Implementation 3

In Figure 3, Line 1 shows the existing conventional railway, Line 2 represents the improved existing conventional railway line after geometrical improvement, and Line 3 presents an alternative track to the existing conventional line. The straight parts, transition curves and curves are shown blue, green and red, respectively.

To improve the conventional line, the following geometrical parameters were used: horizontal curve radius of 5,000 $(\mathrm{min})$ and $15,000 \mathrm{~m}(\max )$, transition curve length of $500 \mathrm{~m}(\mathrm{~min})$ and 1,000 $\mathrm{m}$ (max), maximum and minimum applied cant of $70 \mathrm{~mm}$ and $160 \mathrm{~mm}$, respectively, minimum vertical curve radius of 30,000 $\mathrm{m}$ and maximum gradient of $2.20 \%$. The volume of earthworks, total length of engineering structures and approximate cost calculated for the alternative line of $69,060 \mathrm{~m}$ length are given in Tables 17, 18 and 19, respectively.

\begin{tabular}{|c|c|}
\hline Cut $\left(\mathrm{m}^{3}\right)$ & Fill $\left(\mathrm{m}^{3}\right)$ \\
\hline $8,770,928.08$ & $2,779,890.20$ \\
\hline
\end{tabular}

Table 17. Volume of earthworks required for the improvement of the conventional line on mountainous land

\begin{tabular}{|c|c|}
\hline Bridge $(\mathrm{m})$ & Tunnel $(\mathrm{m})$ \\
\hline 1,830 & 17,330 \\
\hline
\end{tabular}

Table 18. Total length of engineering structures required for the improvement of the conventional line on mountainous land

\begin{tabular}{|c|c|c|c|}
\hline Cut (TL) & Fill (TL) & $\begin{array}{c}\text { Bridge } \\
\text { (TL) }\end{array}$ & Tunnel (TL) \\
\hline $70,167,424.65$ & $25,019,011.73$ & $29,280,000$ & $693,200,000$ \\
\hline & & Total (TL) & $817,666,436.38$ \\
\hline
\end{tabular}

Table 19. Approximate total cost of improving the conventional line on mountainous land

In the second stage of Implementation 3, an 113,170 m alternative track was designed with a $2.20 \%$ gradient. For this line, the minimum horizontal curve radius was taken as $5,000 \mathrm{~m}$, maximum horizontal curve radius as $10,000 \mathrm{~m}$, minimum transition curve length as $500 \mathrm{~m}$, maximum transition curve length as $1,000 \mathrm{~m}$, minimum vertical curve radius as $30,000 \mathrm{~m}$, maximum applied cant as $160 \mathrm{~mm}$ and minimum applied cant as $100 \mathrm{~mm}$. Tables 20, 21 and 23 present the volume of earthworks, total length of engineering structures and approximate cost calculated for the alternative line.

\begin{tabular}{|c|c|}
\hline Cut $\left(\mathrm{m}^{3}\right)$ & Fill $\left(\mathrm{m}^{3}\right)$ \\
\hline $10,605,170.79$ & $3,742,780.19$ \\
\hline
\end{tabular}

Table 20. Volume of earthworks required for the construction of an alternative line on mountainous land

\begin{tabular}{|c|c|}
\hline Bridge $(\mathrm{m})$ & Tunnel $(\mathrm{m})$ \\
\hline 14,530 & 29,940 \\
\hline
\end{tabular}

Table 21. Total length of engineering structures required for the construction of an alternative line on mountainous land

\begin{tabular}{|c|c|c|c|}
\hline Cut (TL) & Fill (TL) & Bridge (TL) & Tunnel (TL) \\
\hline $84,841,366.32$ & $33,685,021.68$ & $232,480,000$ & $1,197,600,000$ \\
\hline \multirow{2}{*}{} & Total (TL) & $1,548,606.39$ \\
\cline { 2 - 3 } & &
\end{tabular}

Table 22. Approximate total cost of constructing an alternative line on mountainous land

\section{RESULTS AND CONCLUSIONS}

The two significant findings of the study can be listed as follows:

- The length of the improved line was shorter than that of the conventional line; however, there was still a need to build new engineering structures and undertake earthworks operations.

- For the improved line, the track length and total length of the engineering structures were shorter, the cost of construction was lower and volume of required earthworks was less compared to the alternative line.

In addition, it has been observed that in the first implementation, in places where the large-diameter curves designed for highspeed trains overlap the straight sections of the existing conventional line, earthworks need to be undertaken only for curved sections. It is considered that this will help reduce the cost and time.

Although the whole conventional line was not analyzed in this study, from the implementations, it was determined that considering the total length of engineering structures, volume of earthworks and costs, it would be much more feasible and quicker to improve the existing line rather than constructing an alternative line.

\section{ACKNOWLEDGEMENTS}

We are very grateful to the Turkish State Railways for their contribution to the realization of this study. 


\section{REFERENCES}

CEN, 2010. "Railway application-Track alignment design parameters- Track Gauges 1435 and wider-Part 1: Plain line, EN 13803-1:2010".

Ekim, O., 2007. "Geometrical Specifications and Infrastructure for High-Speed Railways", Yıldız Technical University, Faculty of Civil Engineering, Department of Transportation, Master's Thesis, Istanbul.

Esveld, C., 2010. "Recent Developments in High Speed Track", Delft University of Technology, The Netherlands.

Hodas, A., 2014. "Design of Railway Track for Speed and Highspeed Railways", University of Žilina, Fac. of Civil Engineering, Dept. of Railway Engineering, Univerzitná 8215/1, SK-01026 Žilina, Slovak Republic.

Lindahl, M., 2001. "Track Geometry for High-Speed Railways", Department of Vehicle Engineering Royal Institute of Technology, Stockholm.

Mundrey, J. S., 2010. "Tracking for High Speed Trains in India”, RITES Journal, January 2010.

SZWACZKIEWICZ，K., 2014. "Earthwork calculations in various field conditions", Gdansk University of Technology, Faculty of Railway Transportation and Bridges, http://www.czasopismologistyka.pl/artykuly-

naukowe/send/318-artykuly-na-plycie-cd-3/7113-artykul, Gdansk, Poland (07.09.2016).

TSI, 2000. "European Association for Railway Interoperability (AEIF): Trans-European High-Speed Railway system, Technical Specification for interoperability (TSI), "infrastructure" Subsystem, Version A", April 2000.

Vermeij, D. J., 2000. "Design of a High Speed Track", Project organisation HSL-Zuid, Utrecth, The Netherlands.

Yalçın, N. S., 2007. "The Importance of Infrastructure and Design Criteria of High Speed Railways", Yıldız Technical University, Faculty of Civil Engineering, Department of Transportation, İstanbul, $7^{\text {th }}$ Transportation Symposium. 